\title{
Conservation of the endemic Pyrenean newt (Calotriton asper) in the age of invasive species: interlake dispersal and colonisation dynamics.
}

\author{
Federica Lucati ${ }^{1,2, *}$, Alexandre Miró $^{1}$ and Marc Ventura ${ }^{1}$ \\ ${ }^{1}$ Centre for Advanced Studies of Blanes (CEAB-CSIC). Accés Cala St. Francesc, 14, 17300, Blanes, Girona, Spain. \\ ${ }^{2}$ Centre for Ecology, Evolution and Environmental Changes (cE3c), Faculty of Sciences, University of Lisbon. Campo \\ Grande, 1749-016 Lisbon, Portugal.
}

*Corresponding author. E-mail: federicalucati@hotmail.com

The aim of the project was to investigate patterns of colonisation of new ecosystems following invasive fish removal and the process of dispersal from nearby populations in the Pyrenean newt (Calotriton asper) (fig. 1), a Near Threatened (NT-IUCN) amphibian endemic to the Pyrenees. We used a multidisciplinary approach that combined genetic (population structure and dispersal analyses) and field-based (mark-recapture using photo-identification) approaches.

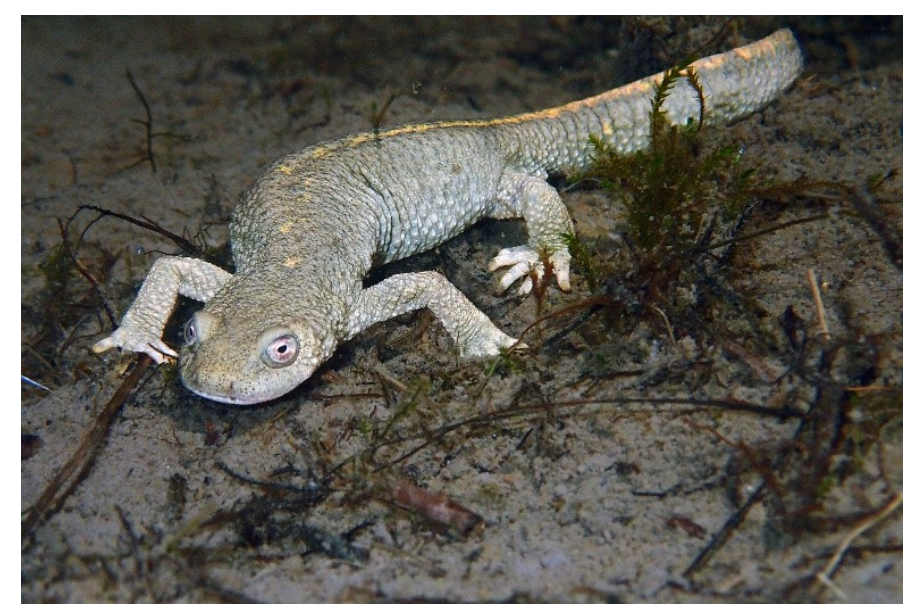

Figure 1. An adult individual of Pyrenean newt (Calotriton asper). Photo by Marc Ventura.

The study site was located in the cirque of Dellui, in the National Park of Aigüestortes i Estany de Sant Maurici (central-eastern Pyrenees). This glacial cirque features six high mountain lakes, of which two are fishless and sustain natural populations of $C$. asper, three are undergoing complete fish eradication and are being colonised by $C$. asper, and one still harbours invasive fish and no newts 
were reported. Fish eradication activities have been ongoing since 2014, with the purpose of returning selected high mountain lakes to their fish-free natural state and allow the recovery of native species such as amphibians (LIFE+ LIMNOPIRINEUS; www.lifelimnopirineus.eu).

SEH funds were the only financial support available for this project in 2018 and were used to cover sampling and laboratory costs. Data collected in 2018 were complemented with those obtained from previous field campaigns in 2016 and 2017.

Assessment of population structure and recent dispersal was conducted through the analysis of 17 nuclear microsatellite markers (Drechsler et al., 2013). In total, 106 individuals from five of the six target lakes were sampled (we did not detect newts in the fish-containing lake). Seven populations (82 individuals) from nearby cirques were also sampled to gain further insights into the dispersal capability of the species. C. asper individual photo-identification was performed through the patternrecognition software $\mathrm{I}^{3} \mathrm{~S}$ Pattern ${ }^{+} 4.1$ (Van Tienhoven et al., 2007), based on the species spotted ventral pattern. Three to six sampling sessions were carried out at four target lakes during the 3-year period.

Population structure analysis revealed three well-supported groups (genetic lineages), corresponding to the geographic areas under study. Dellui lakes clustered together with the adjacent cirque of Corticelles. We found a relatively high degree of migration within the cirque of Dellui that involved 34 individuals across all sampled lakes. Furthermore, we detected two migration events from Corticelles to Dellui. Nonetheless, migration was limited within lineages. The photographic dataset included 125 individuals, 20 of which were recaptured at least once. The species ventral pattern was sufficiently varied to allow for the reliable identification of all individuals and it did not substantially change over the study period. Of the 20 recaptures, only one was found in a lake other than the lake of first collection. The individual in question was first captured at a fishless lake in 2016 and recaptured two years later at one of the restored lakes.

This work emphasizes the high resilience of $C$. asper high-mountain populations after reducing or eliminating the source of perturbation. The species showed a remarkable capability to colonize, establish and spread into new suitable environments when invasive fish predation pressure was reduced, even without complete fish eradication. C. asper was detected within one year of starting fish removal at the restored lakes, and both reproduction and survival of larvae were confirmed. To our knowledge, this is the first study attempting to use computer-assisted photoidentification in a capture-recapture study targeting the Pyrenean newt. Results indicate that the species ventral pattern is highly patterned and stable enough over time to allow for reliable individual identification, and provide an effective alternative to more intrusive approaches. The number of recaptures was low, indicating that a much higher sampling effort is required to disentangle the 
species' dispersal dynamics using this approach. Nevertheless, the only case of interlake dispersal shows the importance of fishless lakes as reservoirs for restored lakes. On the other hand, genetics proved more efficient in characterising patterns of dispersal. The studied populations are genetically and geographically structured and migration usually involved neighbouring lakes. However, we detected evidence of dispersal between adjacent cirques. Finally, this study highlights the importance of combining genetic and field-based approaches to shed light on dispersal dynamics.

\section{Acknowledgements}

We thank Jenny Caner for laboratory assistance, and Jan Tomàs, Blanca Font, Ismael Jurado, Meritxell Cases, Eloi Cruset, David O’Brien and Quim Pou-Rovira for field assistance. We are especially grateful to Alba Castrillón for her help during field work and for photo-identification data processing.

\section{References}

Drechsler A, Geller D, Freund K, Schmeller DS, Kuenzel S, Rupp O et al. (2013) What remains from a 454 run: estimation of success rates of microsatellite loci development in selected newt species (Calotriton asper, Lissotriton helveticus, and Triturus cristatus) and comparison with Illumina-based approaches. Ecol. Evol. 3: 3947-3957.

Van Tienhoven AM, Den Hartog JE, Reijns RA, Peddemors VM (2007) A computer-aided program for pattern-matching of natural marks on the spotted raggedtooth shark Carcharias taurus. J. Appl. Ecol. 44: 273-280. 